\title{
ELECCIÓN SOCIAL, DESIGUALDAD Y VIRTUD CÍVICA
}

Mauricio Uribe López*

Nadie es una isla, completo en sí mismo. John Donne

uillermo O’Donnell, reconocido por sus aportes al estudio del
del Estado y el imperio de la ley en América Latina, publicó a finales
de los noventa un ensayo sobre pobreza y desigualdad que se enmarca
en la concepción de virtud cívica del pensamiento republicano y la
noción de agencia como compromiso social de Amartya Sen.
Según O’Donnell (1998), no basta apelar al miedo o al interés de
los privilegiados para situar la lucha contra la pobreza y la desigualdad
en el centro de la agenda pública. El temor de los más ricos -y las capas
medias- a una rebelión o al aumento de la inseguridad no incentiva su
respaldo político a medidas redistributivas o al fortalecimiento de las
entidades del Estado encargadas de la política social. La cooptación
y la represión son opciones disponibles. El interés en el crecimiento
económico, obstaculizado por la pobreza y la desigualdad ${ }^{1}$, tampoco
suscita un mayor compromiso con la redistribución y las políticas
sociales universalistas ${ }^{2}$, pues plantea un problema de acción colectiva:

* Doctor en Ciencia Política, profesor de la Universidad Eafit, [muribel4@eafit. edu.co]. Fecha de recepción: 19-08-2016, fecha de modificación: 22-06-2017, fecha de aceptación: 04-09-2017. Sugerencia de citación: Uribe L., M. (2017). Elección social, desigualdad y virtud cívica, Revista de Economía Institucional 19(37), 67-84. DoI: https://doi.org/10.18601/01245996.v19n37.04

${ }^{1}$ En un trabajo publicado por el FMI, Ostry, Berg y Tsangarides (2014) muestran que la desigualdad es un determinante del crecimiento a largo plazo, aun si se controlan las transferencias redistributivas.

${ }^{2}$ Sobre el efecto redistributivo de las políticas sociales universalistas y sus ventajas para garantizar el ejercicio de los derechos sociales y el carácter subsidiario de las políticas selectivas o de focalización, ver Ocampo (2008). 
cada propietario o inversionista rico espera que las propiedades o firmas ajenas financien las transferencias a los más pobres.

La conclusión de O'Donnell es que una coalición que se proponga modificar el panorama de pobreza y desigualdad ${ }^{3}-$ y no solo poner en marcha programas remediales- se debe fundar no tanto en los intereses de sus promotores sino en sus valores y juicios morales. En particular, en el valor moral que es la base normativa de la democracia: igual respeto a la autonomía y dignidad de cada individuo. Incluso -recalca el politólogo argentino- la visión minimalista de la democracia como mecanismo para sustituir al gobierno cada cierto periodo, por medio de elecciones competitivas, se basa en la premisa de la autonomía e igualdad de cada votante.

Contra la pretensión de desterrar los juicios en economía y ciencia política ${ }^{4}$, la teoría de la elección social liderada por Kenneth Arrow intenta fundamentar las decisiones colectivas en dichos juicios:

La aceptación del teorema de Arrow implica que la función de bienestar social tiene que ser definida de manera deontológica. Los juicios de valor y la normatividad que subyacen a cualquier función de bienestar social no son ajenos a la teoría económica. Son constitutivos de esta. En contra del planteamiento de Robbins, la ciencia económica tiene que vérselas con los juicios de valor (González, 1994, 21-22).

Aunque Amartya Sen critica el anclaje utilitarista de la teoría de la elección social, reivindica su papel en el desarrollo de una teoría de la justicia desligada del "institucionalismo trascendental" de las teorías deontológicas del contrato social, a las que atribuye tres grandes falencias: 1) la preocupación por caracterizar una sociedad perfectamente justa en vez de resolver las injusticias más apremiantes. En palabras de Arrow: "Nunca hay necesidad de comparar las opciones disponibles con las que no están disponibles para tomar una decisión” $(1986,224) ; 2)$ el diseño de instituciones basado en un conjunto único de principios ${ }^{5}$,

${ }^{3}$ Para O’Donnell, además del altruismo, dos características objetivas hacen de los sectores medios los más apropiados para liderar esa coalición: buen nivel educativo y acceso a la información, y dificultad para asegurar la provisión privada de bienes y servicios públicos y meritorios.

${ }^{4}$ En su deseo de suprimir los juicios morales en economía, los teóricos de la demanda intentaron explicar el comportamiento individual sin referirse a nada distinto del comportamiento mismo (Sen, 1973). El axioma de preferencias reveladas pretendía librar la teoría de la demanda de toda relación con el principio de utilidad. Así, la teoría de la elección racional adquirió un carácter tautológico y la palabra preferencia fue despojada de su significado: "Al decir que $x$ se revela como preferido a $y$, no se estaría afirmando que $x$ es preferido a $y$ en el sentido usual de la palabra preferido" (ibíd., 62).

5 Tal es el caso de la solución única al problema de la elección de diferentes concepciones de justicia en el esquema rawlsiano de la posición original. Esa solución única implica - de acuerdo con la crítica de Sen-desconocer la pluralidad 
y 3) el énfasis exclusivo en las instituciones, perdiendo de vista las injusticias que provoca el comportamiento individual (Sen, 2010).

Sen no es un representante del republicanismo pero tampoco es uno de sus críticos ${ }^{6}$. Aunque son dos enfoques diferentes, el de las capacidades y el republicano coinciden en la relevancia del compromiso de las personas con los demás y con su comunidad política. La concepción de O’Donnell, la teoría de la elección social, el enfoque de capacidades y la tradición republicana atribuyen a las consideraciones morales un papel al menos tan importante como el de los incentivos asociados a la búsqueda de la ventaja individual en la reproducción y reforma del orden social.

Este artículo tiene tres objetivos. El primero es dar cuenta de la manera en que Amartya Sen, al buscar salidas a los problemas frente a la cuestión distributiva, presentes en la regla de la mayoría y en el teorema de la imposibilidad de Arrow, vincula la teoría de la elección social con la búsqueda razonada de la justicia mediante el rescate de las comparaciones interpersonales. Comparaciones que, a diferencia de lo que hace el utilitarismo clásico, parten de considerar diferentes tipos de información moral, incluida la agencia de las personas.

E1 segundo objetivo es mostrar que el concepto seniano de agencia, entendido como compromiso, tiene una estrecha relación con el humanismo cívico de la tradición republicana y la vita activa: la acción política de los ciudadanos en el espacio público, ámbito de despliegue de la virtud cívica para lograr el bien común, de la libertad como participación en los asuntos de la comunidad política y de la igualdad asociada al estatus y a los derechos de la ciudadanía (Béjar, 2000). La noción de compromiso de Sen (1976) tiene cierta sinonimia con la idea de virtud cívica de lo que John Rawls (1993) llama "republicanismo clásico", asociado a los nombres de Tocqueville y de Quentin Skinner.

valorativa y los conflictos irreductibles entre diferentes concepciones de justicia que también pueden reivindicar, cada una, un carácter imparcial.

${ }^{6}$ Philip Pettit (citado por Sen, 2010) sugiere cierta complementariedad entre el enfoque de la libertad republicana como ausencia de poderes arbitrarios que puedan obstaculizar la libertad personal y el enfoque de la libertad basada en las capacidades. Según Pettit, esa complementariedad implica que la libertad republicana podría verse como una extensión del enfoque de Sen. Ante esta sugerencia afirma Sen: "No hay duda de que el concepto republicano de libertad es importante y capta un aspecto de nuestras intuiciones acerca de los reclamos de libertad. Mi discrepancia se refiere a que la idea republicana de libertad puede remplazar la perspectiva de la capacidad como libertad. Hay cabida para ambas ideas, lo cual no tiene que ser fuente de tensión, a menos que insistamos en una idea unifocal de libertad, contra la cual ya he ofrecido mis argumentos" (Sen, 2010, 336). 
E1 tercer objetivo es argumentar que los límites utilitaristas de la teoría de la elección racional no le permiten a esta dar cuenta del sentido de compromiso y responsabilidad hacia los demás que, en el contexto de desigualdades extremas en América Latina, resulta imperativo. Por esa razón, el cambio social no puede provenir exclusivamente del diseño adecuado de incentivos basados en la búsqueda de las ventajas individuales, sino que debe incluir la influencia (mediante la educación y la deliberación democrática) en el alma de los ciudadanos, para crear una cultura política pública que permita elevar el grado de aversión a la desigualdad en la región.

El artículo se divide en tres secciones. La primera presenta el reto planteado por el teorema de la imposibilidad de Arrow y algunos de los principales hallazgos de Amartya Sen en la búsqueda de respuestas al mismo. La segunda expone el consecuencialismo pluralista de Sen y su noción de agencia como compromiso. En la última se presentan algunas conclusiones que recalcan la importancia de tomar en cuenta no solo los incentivos sino también los valores morales asociados a la valoración de lo público y la democracia, para hacer viable el posicionamiento de las políticas redistributivas, apoyadas en un incremento de la aversión de los ciudadanos a la desigualdad.

\section{EL RESULTADO DE ARROWY LA EXPLORACIÓN DE SEN}

En la conferencia de recepción del Premio Nobel en 1972, Kenneth Arrow señaló que, desde la publicación de la Riqueza de las naciones, la preocupación central de la teoría económica era cómo se coordinan las decisiones individuales en el mercado. La pregunta de Adam Smith de cómo alcanzar orden en el caos potencial tuvo una "respuesta razonablemente clara en el decenio de 1870 con el trabajo de Jevons, Menger y, sobre todo, León Walras: el hecho de que todos los agentes de la economía afronten el mismo conjunto de precios proporciona el flujo común de información necesario para la coordinación del sistema" (Arrow, 1972, 157). Arrow retomó el programa de investigación de Walras y lo llevó a su cúspide: la teoría del equilibrio general.

El equilibrio competitivo general nos enseña sobre todo la medida en que puede alcanzarse la asignación social de los recursos mediante decisiones privadas independientes coordinadas por el mercado. Estamos seguros, en efecto, de que tal asignación no solo puede alcanzarse, sino que el resultado será eficiente en el sentido de Pareto. Sin embargo, como hemos subrayado, no hay nada en el proceso que garantice la justicia de la distribución (ibíd., 184).

Una de las principales motivaciones para estudiar la teoría de la elección social entre los economistas ha sido entonces -según señaló 
Arrow- la de hallar una guía para evaluar la distribución del ingreso. Se requería un procedimiento para agregar las preferencias individuales sobre los estados del mundo ${ }^{7}$, en un solo ordenamiento social que respete algunas condiciones básicas:

1. Dominio irrestricto (condición $U$ ): la función de bienestar debe incluir todos los perfiles de preferencias de los individuos.

2. Principio de Pareto (condición $P$ ): un criterio de unanimidad. Si entre dos alternativas $x$ e $y$ unos individuos prefieren $x$ a $y, y$ los demás son indiferentes, $X$ es socialmente preferido a $Y(X \mathrm{P} Y)$.

3. Independencia de las alternativas irrelevantes (condición $I$ ): el ordenamiento social de dos estados del mundo debe depender exclusivamente de los ordenamientos individuales de esos estados. En política, "toda forma de votación satisface [esta condición]; por supuesto, nunca se preguntan ni se toman en cuenta las preferencias de los votantes entre candidatos y no candidatos, o entre no candidatos" (ibíd., 186).

4. No dictadura (D): el teorema de imposibilidad de Arrow afirma que, si hay al menos tres estados del mundo, no habrá una función de bienestar social que satisfaga las condiciones anteriores.

Siguiendo la síntesis de Arrow (1986), la parte final de la prueba es la siguiente. Conforme al principio de Pareto, hay al menos un conjunto decisivo para cualquier par de opciones $(x, y)$, el conjunto de todos los individuos. Considerando la condición $D$, el menor conjunto decisivo posible debe contener al menos dos individuos.

$V$ es el conjunto decisivo mínimo para los pares $(x, y)$. Si dividimos $V$ en $V_{1}$ (que contiene un individuo) y $V_{2}$ (que contiene todos los demás), $V_{3}$ es el conjunto de individuos que no están en $V$. Si tenemos los ordenamientos de preferencias siguientes:

$V_{1}: x \rightarrow y ; y \rightarrow z ; V_{2}: z \rightarrow x ; x \rightarrow y ; V_{3}: y \rightarrow z ; z \rightarrow x$

Como $V$ es decisivo para $x$ frente a $y$, y todos los miembros de $V$ prefieren $x$ a $y$ mientras que los demás tienen la preferencia contraria, entonces $X$ es socialmente preferido a $Y(X \mathrm{P} Y)$. Es imposible que la sociedad prefiera $z$ a $y$, pues $V_{2}$ sería decisivo, lo cual es imposible porque $V_{2}$ es menor que $V$, y $V$ se definió como un conjunto con el mínimo número de miembros de un conjunto decisivo. Si $X \mathrm{P} Y$ y YPZ, entonces $X \mathrm{P} Z$. Es decir, por transitividad, la sociedad debe preferir $x$ a $z$. En ese caso, $V_{1}$ sería decisivo, lo cual es imposible, y es allí donde se expresa la contradicción.

7 “Tomamos de la teoría de la probabilidad el concepto de estado del mundo, una descripción del mundo tan precisa que define por completo todas las dotaciones iniciales de bienes y todas las posibilidades tecnológicas" (ibíd., 182). 
Esta paradoja es antigua. El método de votación por mayoría es un método de elección social atrayente. Como cualquier otro sistema de votación, satisface la independencia de las alternativas inaplicables y el principio de Pareto y la condición de ausencia de dictadura. Pero como observó Condorcet (1785), es posible que la votación por mayoría no conduzca a un ordenamiento. En forma más específica, es posible la intransitividad (Arrow, 1972, 186).

En 1952, Arrow describió su resultado como "el colmo de la mala suerte”. En su discurso Nobel dijo que no eran claras las implicaciones filosóficas de ese resultado y esperaba que otros lo tomaran "como un reto y no como una barrera desalentadora".

La ciencia política ya había iniciado la exploración de salidas en 1948, cuando Duncan Black propuso el teorema del votante mediano: si la distribución de preferencias de los votantes a lo largo de un eje tiene un solo máximo, la preferencia del votante mediano será la preferencia de la mayoría ${ }^{8}$. El óptimo político (la decisión que minimiza la desutilidad) corresponde a la suma mínima de las "distancias" entre las preferencias de los votantes y la decisión social. Esa suma es mínima cuando la decisión social coincide con la preferencia del votante mediano (Colomer, 2000, 19). La mala noticia en el terreno del óptimo político es que la agenda de una sociedad no se define a lo largo de un solo eje (un votante puede estar a la izquierda en políticas redistributivas y a la derecha en derechos de las parejas homosexuales), de modo que diversas mayorías posibles pueden derrotar al votante mediano.

Además, en cuanto a la cuestión distributiva -advirtió Sen (1985)-, la decisión mayoritaria puede no ser satisfactoria: si tenemos tres individuos $(1,2$ y 3$)$ con preferencias totalmente egoístas, un pastel para repartir entre ellos y dos opciones por las que pueden votar: la opción $x$ (distribución igualitaria del pastel) y la opción y $(2$ y 3 se lo dividen entre ellos y 1 se queda sin nada), tendríamos que $Y$ sería preferido socialmente a $X(Y P X)$.

\footnotetext{
¿En qué sentido es $y$ un resultado satisfactorio en este problema de elección? La persona 1 ha sido puesta contra la pared y 2 y 3 han engordado un poco más. Es difícil sostener que la regla de la mayoría es una forma plausible de agregar preferencias para esos juicios de bienestar económico. Este problema se presenta con dos alternativas aún antes de que surja la cuestión de la intransitividad (ibíd., 1767).
}

En busca de una guía para enfrentar el problema de la redistribución, Sen asumió el reto de Arrow. Según Sen, la demostración de

${ }^{8}$ Basado en la analogía del mercado espacial de Harold Hotelling, el teorema supone que, según sus preferencias, los ciudadanos se distribuyen a lo largo de un eje. En un sistema bipartidista, p. ej., cada partido tendría incentivos para moverse hacia el centro y así atraer a los votantes moderados y a sus partidarios de ambos extremos (Downs, 1957, 125). 
la imposibilidad indujo la investigación sobre limitaciones éticas de la economía del bienestar como las que resultaban de renunciar a las comparaciones interpersonales ${ }^{9}$. Limitaciones que John Hicks (1975, 237) reconoció al señalar que algo se había hecho para afrontar el problema de las comparaciones de utilidad, sin salvar el concepto de bienestar económico.

La preocupación de Sen por restaurar el diálogo entre ética y economía ha impulsado un nuevo paradigma del desarrollo en el que el punto focal de las políticas públicas es la libertad de los individuos "para llevar el tipo de vida que tienen razones para valorar" (Sen, 2000, 27). Un desarrollo motivado por su convicción acerca de que hay espacios diferentes al de la utilidad para evaluar la desigualdad.

E1 trabajo de Sen da herramientas para cuestionar la tajante distinción entre ética y economía que defendió Lionel Robbins en los años treinta. Su idea de que a lo sumo se yuxtaponían no era popular en esa época, pero se convertiría en parte del núcleo de la corriente principal de la economía ${ }^{10}$ (Sen, 1987, 21).

\section{NEUTRALIDAD Y PARETIANOS ILIBERALES}

Sen es un duro crítico de la corriente principal y en particular de la elección racional, pero no es un outsider. No se sitúa fuera de la teoría para debatir con ella. No busca anotar goles jugando fuera de la cancha, sino que va al centro mismo de los supuestos de la teoría y desde allí empuja el balón contra la red. No solo reconoce sino que se apoya en la arquitectura teórica del edificio neoclásico, con una mezcla de continuidad y ruptura. Así, por ejemplo, se apoya en el teorema fundamental de la economía del bienestar ${ }^{11}$, pero rompe con

\footnotetext{
9 Arrow era consciente del carácter interpersonal de la elección social. Pero la lógica de la elección en el marco del utilitarismo ordinal y la propiedad de neutralidad del teorema de la imposibilidad llevaron a la teoría de la elección social de Arrow por un camino diferente al de las comparaciones interpersonales.

${ }^{10}$ Ese núcleo se hizo tan refractario a ideas y planteamientos distintos que en 1992 más de cuarenta economistas, entre ellos Herbert Simon, Jan Tinbergen, Franco Modigliani y Paul Samuelson, suscribieron un manifiesto que denunciaba que los economistas no practicaban libre competencia en el campo de las ideas, y exigía un debate más pluralista y más riguroso. Ver "Manifiesto" (1994). Cuadernos de Economía (14)20, 7-8.

${ }^{11}$ La primera parte del teorema afirma que toda asignación de equilibrio alcanzada por el funcionamiento de un mercado perfectamente competitivo es un óptimo de Pareto. La segunda afirma que se puede obtener un óptimo de Pareto a través del mercado competitivo, mediante una redistribución específica de las dotaciones iniciales en función del óptimo seleccionado y dado un conjunto de precios. La teoría de la elección social buscaba encontrar un método para seleccionar dicho óptimo.
} 
su trasfondo utilitarista y propone un criterio para evaluar el mercado en términos de libertad individual (Sen, 1990).

Continúa el trabajo de Arrow en la exploración sistemática de los procedimientos de elección, pero rompe con él y propone salidas a su teorema de la imposibilidad demostrando que los requisitos de transitividad y completitud ${ }^{12}$ no son siempre ambos necesarios ya que esto depende de la naturaleza de la elección. Si $x$ se prefiere a $y, y$ a $z, y z$ es indiferente a $x$, es posible escoger un ganador en cada elección, aunque no haya transitividad. Así mismo, si $x$ se prefiere a $y$ y también a $z$, aún es posible escoger $x$ aunque $y$ y $z$ no sean comparables ${ }^{13}$.

Además, en la búsqueda de una regla para seleccionar una asignación que refleje el ordenamiento de preferencias de los individuos acerca de la distribución, la mala noticia no es solo la intransitividad, sino también la neutralidad. Esta propiedad no es muy perturbadora al votar entre distintos candidatos. Lo que se espera es que las elecciones sean imparciales y que el resultado dependa exclusivamente de las preferencias del electorado. Pero al escoger una distribución determinada del ingreso esa propiedad es muy problemática (Sen, 1985): si tenemos tres individuos: $a, b$ y $c ;$ y los siguientes estados:

1. $P$ : división igualitaria del pastel, $Q$ : nada para $a$ y el pastel se reparte entre $b$ y $c ; \mathrm{y}$

2. $M$ : nada para $b$ ni para $c$ y todo el pastel para $a$; $N$ : división igualitaria del pastel (lo mismo que $P$ ),

dadas las preferencias totalmente egoístas de los tres individuos, $a$ prefiere $P$ a $Q$ y $M$ a $N$. Y b y $c$ prefieren $Q$ a $P$ y $N$ a $M$. Así en el caso $1 Q$ es socialmente preferido a $P$, y en el $2 N$ es socialmente preferido a $M$.

La propiedad de neutralidad plantea que si las preferencias individuales en el caso $1(P, Q)$ son idénticas a las preferencias individuales en el caso $2(M, N)$, la elección social puede sustituir perfectamente el

${ }^{12}$ En la perspectiva de Arrow, los requisitos de racionalidad son: transitividad: si $x$ es al menos tan buena como $y$ e $y$ al menos tan buena como $z, x$ debe ser al menos tan buena como $z$; reflexividad: cada alternativa es tan buena como ella misma. Para Sen esta es tan simple que es mejor considerarla una condición de sentido común y no de racionalidad, y completitud: "para cualquier par de alternativas $x$ e $y, x$ es al menos tan buena como $y$, o $y$ al menos tan buena como $x$ (o quizá ambas)" (Sen, 1970a, 17). En el caso de indiferencia entre dos opciones se afirman las dos cosas: $x$ es al menos tan buena como $y$ e $y$ al menos tan buena como $x$. En el de falta de completitud no se afirma ninguna, porque las opciones no se pueden comparar. Fue la falta de completitud y no la indiferencia lo que mató de hambre al asno de Buridán (Sen, 1973, 68).

${ }_{13} \mathrm{Si}$ una relación de preferencia es reflexiva y transitiva pero no completa, se denomina cuasi-ordenación. En realidad, lo que individuos y colectividades enfrentan la mayoría de las veces son cuasi-ordenaciones pues los requisitos de información de las ordenaciones completas son inmanejables. 
par $(P, Q)$ por el par $(M, N)$, de modo que afirmar que $Q$ es socialmente preferido a $P$ es tan bueno desde el punto de vista social como afirmar que $N$ es socialmente preferido a $M$, pues la neutralidad implica que la elección no depende de las características de cada alternativa sino de las preferencias individuales (ibíd.). Pero afirmar que una distribución igualitaria es tan buena como otra que no lo es resulta bastante inocuo si se quería decir algo útil sobre la distribución. La neutralidad excluye el principio de la diferencia de Rawls (1971).

Sen obtuvo otros resultados inquietantes. Es el caso de la imposibilidad de un liberal paretiano ${ }^{14}$. Ese teorema es ilustrado con un ejemplo divertido. Tenemos dos individuos: uno mojigato y el otro no, y un ejemplar de El amante de Lady Chatterley. La preferencia del mojigato es que nadie lea el libro (z). Pero si alguien debería leerlo sería él; ejerciendo como censor del erotismo deja la lectura para sí $(x)$ y evita que el otros se corrompa $(y)$. La preferencia del no mojigato es que el mojigato lo lea para deleitarse con la posibilidad de que se escandalice $(x)$. De no ser así, el no mojigato prefiere leerlo $(y)$ a que nadie lo lea $(z)$.

Si se ha de elegir entre $x$ y $z$, los valores liberales (condición $L^{*}$ ) exigirían-dice Sen- que la sociedad prefiera $z$ a $x$ ya que nadie puede obligar al mojigato a leer el libro si no quiere. Si la elección es entre $y$ $\mathrm{y} z$, la sociedad debe preferir $y$ porque no puede privar al no mojigato de leer un libro que disfrutaría. En el ordenamiento liberal de preferencias sociales $y$ sería preferido a $z, \mathrm{y} z \mathrm{a} x$. Pero $y$ es inferior en el sentido de Pareto porque el mojigato y el no mojigato preferirían que el primero lea el libro, es decir, ambos prefieren $x$. El resultado liberal es incompatible con el óptimo de Pareto y cualquier otra solución posible "es superada por alguna otra solución, dados el principio de Pareto y el principio del liberalismo" (Sen, 1970a, 258). Un hallazgo que plantea un conflicto entre eficiencia paretiana y libertad.

\section{ATAQUe A LA PREFERENCIA REVELADA}

Sen cuestiona uno de los cimientos de la elección racional: la preferencia revelada. Antes de Pareto, la economía del bienestar se apoyaba

\footnotetext{
${ }^{14}$ El teorema II (que relaja la condición de liberalismo del teorema I) afirma que ninguna función de decisión social puede satisfacer simultáneamente las condiciones $U, P$ y $L^{*}$. Las condiciones $U$ y $P$ son las mismas del teorema de Arrow. La condición $L^{*}$ (liberalismo mínimo) consiste en que "hay al menos dos individuos tales que para cada uno de ellos haya al menos un par de opciones en el que él es decisivo, es decir, un par de $x, y$ tal que si el individuo prefiere $x$ (o $y$ ) a $y$ (o $x$ ), la sociedad deberá preferir $x$ (o $y)$ a $y(o x)$ " (Sen, 1970b, 255).
} 
en la noción de utilidad cardinal ${ }^{15}$, ligada al principio de utilidad marginal decreciente, desarrollado en la segunda mitad del siglo XIX por la revolución marginalista protagonizada por William S. Jevons, Carl Menger, Francis Edgeworth, León Walras y Alfred Marshall. La noción de utilidad como cantidad de satisfacción presenta algunas dificultades. Si entre dos bienes $x$ e $y$ un individuo elige $x$, se podría pensar que la satisfacción que le produce $x$ es mayor que la que obtiene de $y$. El problema es que no se puede medir la magnitud de esa diferencia. Peor aún, la utilidad que obtienen dos individuos diferentes al consumir un mismo bien puede diferir notablemente. Cada individuo tendría su propia función de utilidad, lo que impide la comparación interpersonal.

No podemos tomar la temperatura cuando no debemos usar un solo termómetro sino un número inmenso de termómetros diferentes, que funcionan por principios diferentes y sin ninguna correlación necesaria entre sus registros (Hicks, 1939, 78-79).

En los años cuarenta y cincuenta, William Vickrey y John Harsanyi propusieron una "métrica probabilística" de la utilidad basada en los axiomas de elección bajo riesgo enunciados en 1944 por John von Neumann y Oskar Morgenstern ${ }^{16}$.

E1 principal problema de la "métrica probabilística" para medir la utilidad cardinal es el supuesto de que los individuos comparten una actitud similar ante el riesgo (hipótesis de similaridad o isomorfismo de Harsanyi). Con esa hipótesis, el intento de rescatar las comparaciones interpersonales de utilidad cae en la misma trampa que gran parte de los intentos neoclásicos de microfundamentación: la de terminar considerando un agente representativo. Sen la critica por dos razones: primera, duda que la utilidad se pueda medir como actitud ante el riesgo; segunda, los individuos, que son muy diversos, no coinciden en dicha actitud (Sen, 1984).

Si no es posible medir la cantidad de satisfacción de cada elección, tampoco es posible hacer comparaciones interpersonales de utilidad, y menos aún conocer la utilidad total de un grupo. El criterio que guiaba la economía del bienestar pre paretiana, la maximización de la utilidad total, era impracticable. Pareto abrió una vía de escape al proponer que se cambiara la idea de utilidad como cantidad de satisfacción por la de utilidad como elección. Así sustituyó la cardinalidad por una escala, un orden de preferencias: la utilidad ordinal. "Entre las

15 Arthur Pigou bautizó el campo normativo de la economía como economía del bienestar. De ahí que la economía del bienestar preparetiana o cardinal se conozca como economía del bienestar de Pigou.

${ }^{16}$ Para una descripción clara del procedimiento, ver Van Paris (1993). 
contribuciones de Pareto -afirmó Hicks (1934, 21)- quizá ninguna supere la importancia de su demostración de la inconmensurabilidad de la utilidad".

De modo que si entre dos bienes $x$ e $y$ un individuo elige $x$, se puede decir que reveló su preferencia por $x$, pues en su orden de preferencias $x$ antecede a $y$. No importa cuánto difieran las funciones de utilidad -las cuales no se conocen-de dos individuos que escojan $x$ entre $x \mathrm{e}$ $y$; pero se puede afirmar que tienen el mismo orden de preferencias. La utilidad individual no se agrega, se ordena, y así desaparecen las comparaciones interpersonales. De funciones de utilidad desconocidas, gracias a lo que revela la elección individual, se obtienen escalas de preferencias; pero de estas no se puede pasar a funciones de utilidad. Esto ayudó a los teóricos de la demanda -y de la teoría de la elección racional- a liberarse de todo principio moral, incluido el principio de utilidad.

Pareto echó los cimientos sobre los que se construyó la nueva economía del bienestar (de Kaldor-Hicks, cuya piedra angular es la noción de la preferencia revelada), así como el campo de la elección racional, lo que muy pronto avizoró Hicks: "Al transformar la teoría subjetiva del valor en una lógica general de elección, extiende su aplicabilidad a grandes campos de la conducta humana" $(1934,23)$.

Pero Sen encuentra fallas importantes en la lógica seductora de la teoría de la elección racional. Según la noción de preferencia revelada, si un individuo elige $x$ y no $y$ es porque "prefiere" a $x$ sobre $y$. Y si elige $y$ esa es su opción "preferida". El comportamiento depende de las preferencias, pero a estas las define el comportamiento. Ese es el cimiento tautológico del edificio de la elección racional. Un individuo racional sería aquel que no cambia de opinión según la lógica prescrita "en este mundo encantado de las definiciones" (Sen, 1976, 181).

Este enfoque del egoísmo definicional recibe a veces el nombre de elección racional, e implica nada menos que la consistencia interna [...] Se consideran "racionales" las elecciones de una persona si todas estas elecciones pueden explicarse en términos de alguna relación de preferencia consistente con la definición de la preferencia revelada [...] Presupone a la vez demasiadas cosas y demasiado poco: esto último porque hay algunas fuentes de información sobre la preferencia y el bienestar diferentes de las elecciones, tal como se suele entender estos términos; y lo primero porque la elección puede reflejar una transacción entre diversas consideraciones, una de las cuales puede ser el bienestar personal (ibíd., 181-182). 


\section{EL PLURALISMO DE SEN Y LA AGENCIA COMO COMPROMISO}

Los individuos no tienen preferencias unívocas e inequívocas y no siempre su opción óptima es maximizadora, en especial porque muchas de sus elecciones no se limitan a un conjunto único de alternativas sino que se extienden a varios conjuntos, pues sus motivaciones son diversas y además están impregnadas de juicios morales. Quien no cede el puesto a una mujer embarazada quizá alcance el óptimo individual en el ordenamiento de $x$ e $y$, donde $x$ es viajar cómodo e $y$ viajar incómodo, si esas dos opciones son todo lo que se ha de tomar en cuenta. Pero la elección racional subestima el hecho de que las personas son seres sociales y que sus preferencias no están atadas rígida y exclusivamente a sus propias preferencias (Sen, 1973, 73). Un acto de elección para el animal social que es el ser humano -reitera- es siempre, en un sentido fundamental, un acto social. Así que lo que puede ser óptimo para el individuo aislado, puede no serlo para el ser social.

Los juicios morales toman la forma de un ordenamiento más amplio. En ese metaordenamiento, a representa tener consideración hacia los demás y $b$, no tenerla. Si se trata de un individuo cínico, carente de sensibilidad moral, su metapreferencia será $b$ sobre $a$, y el resultado de su elección será $x$. Pero si se trata de un ciudadano virtuoso, su metapreferencia será $a$ sobre $b$ y estará dispuesto a elegir $y$. Entre "viajar cómodo" y "viajar incómodo", el ciudadano virtuoso prefiere viajar cómodo, pero elige viajar incómodo, pues el compromiso -dice Sen- pone una cuña entre elección y preferencia.

Si se trata de un individuo incapaz de formular una relación de metapreferencia porque no puede distinguir otros conceptos diferentes de la utilidad, se trata de un tonto racional: "el hombre puramente económico es casi un retrasado mental desde el punto de vista social" (Sen, 1976, 202).

Si el individuo sigue sentado, todo lo que el teórico de la elección racional podría decir de él es que prefiere la comodidad. Si se pone de pie el teórico diría que le es más satisfactoria la incomodidad, o en el mejor de los casos, que ceder el puesto a una mujer embarazada le proporciona, por simpatia ${ }^{17}$, más utilidad que negárselo. Haga lo que haga, nunca dejará de decir que el individuo elige lo que prefiere. El teórico de la elección racional no puede reconocer situaciones en las

17 "Debemos distinguir entre dos conceptos distintos: la simpatía y el compromiso. El primero corresponde al caso en que el interés por otros afecta nuestro propio bienestar. Si saber que se tortura a otros nos enferma, este es un caso de simpatía; si no nos enferma, pero creemos que es algo malo y estamos dispuestos a hacer algo para detenerlo, es un caso de compromiso" (ibíd., 187). 
que se actúa guiado por el sentido del deber más que por la ventaja individual.

Aunque la teoría económica neoclásica y la introducción del "método económico" de elección racional a la ciencia política ${ }^{18}$ dan cuenta del hecho indiscutible de que en decisiones de mercado y en decisiones políticas "las oportunidades de beneficio obvias rara vez no se explotan" y que "un billete de veinte dólares no permanece en el suelo de una calle transitada durante mucho tiempo" (Krugman, 1995, 72), la teoría de la elección racional solo ofrece una comprensión limitada-aunque no por ello carente de valor ${ }^{19}$ - del comportamiento y las motivaciones humanas. Es lógico que así sea, porque el monismo de la elección racional solo considera un tipo de información moral relevante: la propia ventaja individual.

Colomer (1991, 13-14) aclara que el interés personal al que se refiere la elección racional "no es necesariamente económico". Otras motivaciones, como "tranquilizar la conciencia ética ante posibles reproches de otras personas" o el placer estético, "son tan aceptables en campos" propios de la elección racional "como la motivación económica habitual de aumentar la renta o la riqueza, o la auténticamente política de conseguir mayor influencia o poder". Con esta aclaración reduce esa "pluralidad de fines" a una medida de utilidad, en este caso, ordinal. No importa si se trata de un "egoísta recalcitrante o un altruista delirante", siempre aparecerá maximizando su propia utilidad (Sen, 1976, 181).

La "pluralidad de fines" de la que habla Colomer es codificada por la teoría de la elección racional en términos de lo que Sen llama "logros de bienestar”. Las trampas tautológicas en las que cae la elección

\footnotetext{
${ }^{18} \mathrm{La}$ introducción de tres elementos metodológicos clave: 1) individualismo metodológico: solo "cabe atribuir voluntad, estrategia, decisión y persecución de objetivos de un modo consciente" a los individuos; 2) racionalidad: los individuos tienen "una capacidad intelectual de deliberación y coherencia" que les permite "elegir los medios que cada uno considera más adecuados para conseguir sus objetivos específicos", y 3) consecuencias no intencionadas: en algunos casos, "los vicios privados -como decía Mandeville- producen virtudes públicas; en otros casos - como ha subrayado cierta crítica del utopismo contemporáneo- las mejores intenciones solo contribuyen a empedrar el infierno" (Colomer, 1991, 12-17).

${ }^{19}$ Cabe reconocer que la teoría de la elección racional, no obstante sus debilidades, proporciona una visión de la política que toma nota de los incentivos más recurrentes. Como planteó Frank Hahn (1983), ninguna teoría del poder y del conflicto puede hacer caso omiso de la frecuencia con que los actores buscan su ventaja, aunque esta no sea siempre, como recuerda Sen, la única motivación. La teoría de la elección racional también propone diseños institucionales que, aunque tomen nota del contexto y del orden social para el que se proponen, no pierdan de vista la importancia de los incentivos.
} 
racional se deben a su consecuencialismo monista (teleológico) ${ }^{20}$. Al que Sen opone un pluralismo que considera cuatro tipos de información moral relevante:

\begin{tabular}{ll}
\hline Faceta de bienestar & Faceta de agencia \\
Logros de bienestar & Logros de agencia \\
Libertad de bienestar & Libertad de agencia \\
\hline
\end{tabular}

La distinción entre logros y libertad en cada faceta se debe a la importancia que Sen atribuye a los procesos y no solo a los resultados. No solo importa el efecto de culminación sino también el efecto comprehensivo. Por ejemplo, en la faceta de bienestar dos personas pueden compartir el mismo resultado: tener hambre. Pero una tuvo libertad de bienestar (decidió ayunar) y la otra no pudo conseguir alimento. Es obvio que estos dos resultados no se pueden evaluar del mismo modo (Sen, 1987, 77). Y su distinción es crucial a la hora de evaluar los resultados de una política pública.

La distinción entre faceta de bienestar y faceta de agencia se justifica por dos razones: en primer lugar, porque el bienestar personal y lo que se cree que es justo, aunque estén relacionados, son dos cosas diferentes (ibíd., 60-61). Si un rico prefiere una distribución equitativa a otra desigual que lo beneficia, no ha de ser necesariamente porque la reducción del sufrimiento del pobre le proporciona más utilidad que la que pierde con la disminución de su ingreso. Quizá considere que su deber es preferir una sociedad justa. Luego de dar un ejemplo mejor, tomado de un drama de Bernard Shaw, Sen afirma: "La característica del compromiso que me interesa más aquí es que mete una cuña entre la elección personal y el bienestar personal, y gran parte de la teoría económica se basa en la identidad de ambos" $(1976,191)$.

En segundo lugar, aunque la elección de bienes en el mercado pueda ser un asunto de "gustos" y la elección de un estado social un asunto de "valores", la distinción - dice Arrow- no se puede establecer, en forma lógica, para las preferencias de un individuo aislado. "Si hay alguna distinción entre valores y gustos, tendrá que residir en el terreno de las relaciones interpersonales"(Arrow, 1967, 220). Y, justamente a lo que se renuncia con el utilitarismo ordinal, base informativa de la elección racional, es a las comparaciones interpersonales.

La idea de agencia da cuenta de un tipo de motivaciones humanas relevantes en la elección social que escapan al ámbito utilitarista de la elección racional. Un tonto racional no puede diferenciar lo que

${ }^{20}$ E1 consecuencialismo es un requisito elemental del utilitarismo como principio moral que plantea que "cada elección, ya sea de acciones, instituciones, motivaciones, normas, etc., se determine por la bondad del estado social consiguiente" (Sen, 1987, 57). 
le produce bienestar de lo que es correcto según ciertas instituciones -bien sean formales o informales, reglas escritas o normas socialesque regulan el comportamiento individual. El tonto racional puede entrar en un templo religioso con el sombrero puesto una y otra vez sin entender jamás las miradas de reproche de los fieles ${ }^{21}$. Si no puede distinguir las reglas, menos aún puede abrigar un sentido del deber, el cual está en el corazón del concepto de agencia.

\section{REFLEXIÓN FINAL: DESIGUALDAD Y VIRTUD CÍVICA}

A diferencia de la teoría de la elección racional, para la cual las preferencias carecen de contenido moral, en la teoría de la elección social las preferencias individuales están asociadas no a gustos sino a valores: "Quizá deseemos reservar el término valores a un conjunto de elecciones especialmente elevadas o nobles. Quizá deberíamos llamar gustos a las elecciones en general" (Arrow, 1986, 220). Como ya se señaló, esa distinción no se hace, sin embargo, en un sentido lógico sino en un sentido subjetivo, por cuanto un sistema de valores es una regla que usa un individuo para escoger entre alternativas (estados del mundo, políticas públicas) mutuamente excluyentes.

$\mathrm{E} 1$ individuo que elige es un ser social, sus valores son moldeados por la sociedad. Por ello, en su intento de microfundamentar las decisiones sociales, la teoría de la elección social se encuentra con la sociedad: "Aun el acto de decisión individual más simple implica la participación de toda una sociedad” (ibíd., 226).

Si los valores individuales reflejan valores sociales es necesario reconocer la influencia de la sociedad en las elecciones y el comportamiento de las personas para trazar el camino de ida y vuelta, entre juicios morales y políticas públicas, que debe recorrer toda propuesta de reforma social. Si una sociedad tiene poca aversión a la desigualdad -como tiende a suceder en América Latina- ninguna política redistributiva será viable si solo depende del diseño de incentivos basado en ventajas individuales. También debe promover la virtud cívica. La lucha contra la desigualdad no puede quedar únicamente en manos de mecanismos sociales activados por la interacción de motivaciones egoístas: "Cuando una organización se administra totalmente mediante

${ }^{21}$ El ejemplo del sombrero es tomado de Helmke y Levitsky (2006) -aunque la versión original parece ser de Herbert Hart-, quienes lo usan para distinguir entre una institución informal y una regularidad informal del comportamiento. Según ellos, lo que hace que quitarse el sombrero en un templo sea una institución informal es que no hacerlo provoca desaprobación o sanción social. Quitarse el abrigo en un restaurante es más una regularidad informal del comportamiento, una costumbre, pero no una institución informal porque dejárselo puesto puede ser incómodo pero no provoca reproche social. 
incentivos de ganancia personal se está condenado al fracaso" (Sen, 1976, 201). Y la desigualdad extrema en América Latina es una señal de fracaso social que se expresa, en general, en baja calidad de la democracia y altos niveles de violencia.

La idea de virtud cívica está relacionada con el concepto de agencia como compromiso de Amartya Sen y con la invitación de O’Donnell a promover una coalición que ponga la lucha contra la pobreza y la desigualdad en el centro de la agenda pública. O’Donnell no busca imponer un solo ideal de vida buena para todos los ciudadanos, sino despertar la sensibilidad moral ante las privaciones y desventajas ajenas y traducirla en acción política. Por ello la perspectiva republicana de la virtud cívica no se entiende aquí en el sentido perfeccionista de John Pocock ${ }^{22}$.

No es necesaria una visión perfeccionista para reconocer que el "compromiso con los valores democráticos implica un ideal de redistribución del ingreso y la riqueza" (Arrow, citado por Feiwel, 1987, 463). En ese sentido, la virtud cívica está vinculada a la responsabilidad que tenemos hacia los demás:

Como seres humanos competentes, no podemos eludir la tarea de juzgar cómo son las cosas y qué es necesario hacer. Como criaturas reflexivas, tenemos capacidad para contemplar la vida de otros. Nuestro sentido de la responsabilidad no tiene por qué referirse solo a las aflicciones que puede causar nuestro propio comportamiento (aunque eso también puede ser muy importante), sino también, en términos más generales, a las miserias que observamos a nuestro alrededor y que está a nuestro alcance remediar (Sen, 2000, 338-339).

Por ese sentido de responsabilidad hacia los demás, O’Donnell urge a los ciudadanos de América Latina que tienen el privilegio de poder hacer algo más que sobrevivir (los sectores medios) a que expresen su compromiso social. Esto no significa alentar la filantropía -únicamente-, pues de lo que se trata es de modificar el panorama general de pobreza y desigualdad. La virtud cívica se ejerce en el ámbito político. $\mathrm{Y}$ es allí donde se manifiesta, en últimas, la viabilidad de la ciudadanía y, por tanto, la idea de igualdad. La reducción de la aversión a la desigualdad requiere trasegar el camino de ida y vuelta entre el alma de los ciudadanos y las políticas públicas, pasando por la cultura política pública.

\footnotetext{
${ }^{22}$ En el republicanismo de Pocock (1975), un "humanismo cívico", el ciudadano debe ser perfecto para garantizar que la comunidad alcance la perfección.
} 


\section{REFERENCIAS BIBLIOGRÁFICAS}

1. Arrow, K. (1972). E1 equilibrio económico general: propósito, técnicas analíticas, elección colectiva. Los premios Nobel de economía 1969-1977 (pp. 155-189). México DF: Fondo de Cultura Económica.

2. Arrow, K. (1986). Valores y toma de decisiones. F. Hahn y M. Hollis (eds.), Filosofía y teoría económica (pp. 218-250). México DF: Fondo de Cultura Económica.

3. Béjar, H. (2000). El corazón de la República: avatares de la virtud politica. Barcelona: Paidós.

4. Colomer, J. (1991). Estudio introductorio. Lecturas de teoría política positiva (pp. 9-33). Madrid: Instituto de Estudios Fiscales.

5. Colomer, J. (2000). Instituciones politicas. Barcelona: Ariel.

6. Downs, A. (1957). Teoría económica de la democracia. Madrid: Aguilar.

7. Feiwel, G. R. (1987). Opiniones de Arrow sobre la equidad, la eficiencia y la democracia. El Trimestre Económico, 54(215), 457-485.

8. González, J. I. (2006). Ética, economía y políticas sociales. Medellín: Corporación Región.

9. Hahn, F. (1983). La teoría del equilibrio general. D. Bell y I. Kristol (eds.), Crisis de la teoría económica. Buenos Aires: El Cronista Comercial.

10. Helmke, G. y Levitsky, S. (2006). Introduction. G. Gretchen y S. Levitsky (eds.), Informal institutions and democracy: Lessons from Latin America (pp. 1-30). Baltimore: The Johns Hopkins University Press.

11. Hicks, J. (1934). Una reconsideración de la teoría del valor. J. Hicks (ed.), Riqueza y bienestar. Ensayos sobre teoría económica (pp. 19-71). México DF: Fondo de Cultura Económica.

12. Hicks, J. (1939). Fundamentos de la economía del bienestar. J. Hicks (ed.), Riqueza y bienestar. Ensayos sobre teoría económica (pp. 75-93). México DF: Fondo de Cultura Económica.

13. Hicks, J. (1975). Alcance y situación de la economía del bienestar. J. Hicks (ed.), Riqueza y bienestar. Ensayos sobre teoría económica (pp. 234-255). México DF: Fondo de Cultura Económica.

14. Krugman, P. (1997). Desarrollo, geografía y teoría económica. Barcelona: Antoni Bosch.

15. Mejía Q., O. (2008). Legitimidad, desobediencia civil y estabilidad. E1 giro hegeliano republicano en la teoría política de John Rawls. J. I. González y M. Pérez (eds.), Pluralismo, legitimidad y economía politica. Ensayos críticos sobre la obra de John Rawls (pp. 107-129). Bogotá: Universidad Externado de Colombia y Universidad Nacional de Colombia.

16. O'Donnell, G. y Tokman, V. (1998). Poverty and inequality in Latin America. Some political reflections. V. Tokman y G. O’Donnell (eds.), Poverty and inequality in Latin America. Issues and new challenges (pp. 49-69). Notre Dame, in: University of Notre Dame Press.

17. Ocampo, J. A. (2008). Las concepciones de la política social. Nueva Sociedad, 215, 36-61.

18. Ostry, J.; Berg, A. et al. (2014). Redistribution, inequality, and growth. IMF discussion note. [https://www.imf.org/en/Publications/ Staff-Discussion-Notes/Issues/2016/12/31/Redistribution-Inequalityand-Growth-41291] 
19. Pocock, J. G. (1975). The machiavellian moment. Reino Unido: Princeton University Press.

20. Rawls, J. (1993). Liberalismo politico. México DF: unam y Fondo de Cultura Económica.

21. Sen, A. (1970a). Elección colectiva y bienestar social. Madrid: Alianza Editorial.

22. Sen, A. (1970b). La imposibilidad de un liberal paretiano. F. Hahn y M. Hollis (eds.), Filosofía y teoría económica (pp. 251-262). México DF: Fondo de Cultura Económica.

23. Sen, A. (1973). Behaviour and the concept of preference. J. Elster (ed.), Rational Choice (pp. 60-81). Oxford: Basil Blackwell.

24. Sen, A. (1976). Los tontos racionales: una crítica de los fundamentos conductistas de la teoría económica. F. Hahn y M. Hollis (eds.), Filosofía y teoría económica (pp. 251-262). México DF: Fondo de Cultura Económica.

25. Sen, A. (1984). El bienestar y la libertad. A. Sen (ed.), Bienestar, justicia y mercado (pp. 61-84). Barcelona: Paidós.

26. Sen, A. (1985). Social choice and justice: A review article. Journal of Economic Literature, 23(4), 1764-1776.

27. Sen, A. (1987). Sobre ética y economía. Madrid: Alianza Editorial.

28. Sen, A. (1990). Mercados y libertades: logros y limitaciones del mecanismo de mercado en el fomento de las libertades individuales. A. Sen (ed.), Bienestar, justicia y mercado (pp. 123-156). Barcelona: Paidós.

29. Sen, A. (2000). Desarrollo y libertad [1999]. Barcelona: Planeta.

30. Sen, A. (2010). La idea de la justicia [2009]. Bogotá: Taurus.

31. Van Parijs, P. (1993). ¿Qué es una sociedad justa? Introducción a la práctica de la filosofía politica. Barcelona: Ariel. 